\title{
Co-design de um Agente Inteligente Conversacional para melhora da saúde de idosos
}

\author{
Mateus de Souza Monteiro \\ Universidade Federal Fluminense \\ Niterói-RJ, Brasil \\ mateusmonteiro@id.uff.br \\ Flavio Luiz Seixas \\ Universidade Federal Fluminense \\ Niterói-RJ, Brasil \\ fseixas@ic.uff.br
}

\author{
Luciana Cardoso de Castro Salgado \\ Universidade Federal Fluminense \\ Niterói-RJ, Brasil \\ luciana@ic.uff.br \\ Rosimere Santana \\ Universidade Federal Fluminense \\ Niterói-RJ, Brasil \\ rfsantana@id.uff.br
}

\begin{abstract}
RESUMO
Um dos principais desafios da sociedade é o envelhecimento da população. Em uma cidade de médio porte no Brasil, São Gonçalo, o Serviço de Atendimento Domiciliar é oferecido aos idosos com mobilidade reduzida. No entanto, devido ao alto índice de violência em certas áreas, constantemente os profissionais que atendem aos idosos sofrem impedimento as visitas. Neste sentido, com o propósito de minimizar parte destes desafios, como por exemplo o contato entre pacientes e profissionais, esta pesquisa propõe o uso de Agentes Inteligentes Conversacionais como um meio de execução do Tele-cuidado. Através de um estudo participativo, este trabalho buscou entender como as características do contexto foram refletidas no design do agente. Após a análise dos resultados foi possível identificar diversas características sociais presentes nos diálogos. Além disso, os participantes também buscaram elaborar soluções que estivessem dentro da realidade econômica dos idosos.
\end{abstract}

\section{INTRODUÇÃO}

Um dos principais desafios da nossa sociedade é o envelhecimento da população [5]. No cenário desta pesquisa, em uma cidade de médio porte do Brasil, os idosos sofrem com altas taxas de analfabetismo, pobreza e também deficiência motora. Com o objetivo de atender estes idosos que necessitam de uma maior frequência de cuidado multiprofissional

Permission to reproduce or distribute, in whole or in part, material extracted from this work, verbatim, adapted or remixed, as well as the creation or production from the content of such work, is granted without fee for noncommercial use, provided that the original work is properly credited.

IHC 2019 - TRILHA PÔSTERES E DEMONSTRAÇÕES. In Anais Estendidos do XVIII Simpósio Brasileiro sobre Fatores Humanos em Sistemas Computacionais. Porto Alegre: SBC, Outubro 21-25, 2019, Vitória, Brasil

(C) 2019 by the author(s), in accordance with the terms of the Creative Commons Attribution-NonCommercial 4.0 International Public License (CC BY-NC 4.0). ou possuem mobilidade reduzida, atua o Sistema de Atenção Domiciliar (SAD). No entanto, os profissionais de saúde que atendem estes pacientes, constantemente sofrem com impedimentos às visitas, em decorrência de fatores como o contínuo medo da violência nessas regiões [4].

Com o propósito de minimizar parte destes desafios, como o contato entre os pacientes e estes profissionais, esta pesquisa propõe o uso de Agente Inteligente Conversacional (AIC) como um meio para a execução do Tele-cuidado. Vale ressaltar que o uso de agentes neste cenário não propõe a substituição do contato humano, essencial para a superação da solidão e do declínio cognitivo e emocional dos idosos [3]. Em uma recente pesquisa realizada na cidade, foi apontado uma necessidade de intervenção na prevenção de complicações clínicas de idosos que sofrem com Doenças Crônicas Não Transmissíveis (DCNT), podendo o agente atuar neste cenário [2]. Na primeira etapa desta pesquisa, conduziu-se um estudo exploratório qualitativo com a participação de profissionais de saúde que atuam no atual serviço de atenção domiciliar. Sabendo da necessidade do balanceamento das questões tecnológicas e sociais [1], esta primeira etapa teve por objetivo responder: Quais reflexões sociais, econômicas e éticas do contexto que os profissionais de saúde estão inseridos refletem no design participativo de agentes inteligentes?

Para tanto, adotou-se conceitos de co-design e práticas de Design Thinking [6] para o levantamento de informações referente às relações do cenário, uma vez que não foram encontradas metodologias específicas para co-criação de diálogos de agentes inteligentes, sem vínculo à tecnologias específicas. Por fim, esta pesquisa se diferencia de trabalhos disponíveis na literatura em diversas formas, principalmente no aspecto de envolver parte dos membros do espaço de pesquisa desde o início do desenvolvimento do agente até a fase de coleta e criação dos diálogos. Na próxima seção, apresentamos o estudo e os resultados obtidos. E finalmente, na Seção 3 as conclusões. 


\section{ESTUDO}

Este estudo tem como objetivo responder a questão de pesquisa citada na Seção 1. Para isso foi realizado um estudo exploratório qualitativo com conceitos de co-design e práticas de Design Thinking [6].

\section{Metodologia}

Dois pesquisadores em Interação Humano-Computador participaram do estudo, um no papel de mentor da discussão e outro responsável por dar suporte à dinâmica. $\mathrm{O}$ estudo foi dividido em três fases: Imersão, Ideação e Prototipação. Os participantes responderam o termo de consentimento livre e esclarecido desta pesquisa. Os dados empíricos coletados foram as falas e imagens dos participantes durante todo o processo do estudo. A análise dos dados seguiu o paradigma não-preditivo e interpretativo com a abordagem de codificação dos dados empíricos coletados e transcritos. Foram selecionados dois profissionais de saúde baseado em suas experiências técnicas/científicas/práticas prévias com idosos e conhecimento do cenário. Ambos os selecionados possuem suas pesquisas voltadas para o cenário do SAD da cidade citada na seção de Introdução. Além disso, um dos participantes possui experiência trabalhando em cenários críticos de home care como gerente de um setor de Tele-cuidado.

\section{Resultados}

Durante a fase de imersão e entendimento do contexto, foi identificado o quanto a esposa de um idoso com DCNT carece de acompanhamento. Isso se deve principalmente a uma questão cultural no perfil dos idosos masculinos atendidos, no qual, não há uma cultura de autocuidado e atenção a própria saúde. Neste caso, deixando toda a responsabilidade para a esposa, contrariando as estatísticas do sistema do próprio $\mathrm{SAD}$, que indicam o perfil de filho como o mais prevalente dentre o perfil dos cuidadores. Segundo os participantes, muitas vezes a esposa não tem o conhecimento técnico para realizar a função de cuidadora. Durante a construção do diálogo, os participantes propuseram o uso de mensagens que transmitissem valorização de um bom trabalho, pois, de acordo com um dos participantes, os cuidadores precisam ser reconhecidos quando executam um bom trabalho.

Além disso, mensagens com teor de alerta também poderiam ser utilizadas na indicação de que algo deve ser mudado e quando há a necessidade emergencial de verificação em um posto de saúde, pois a situação já se encontra crítica. Outro ponto social identificado foi a negligência, pois existe a possibilidade do idoso ou do próprio cuidador dizer que irá fazer e acabar se esquecendo ou apenas não correspondendo com o combinado. Outra característica identificada é a necessidade de uma postura incisiva quando necessário, uma vez que a pressão não foi medida e nem a insulina ingerida, então os participantes são orientados pela mensagem "Meça agora!". Isto se deve principalmente pela necessidade de diálogos que representem clareza e não dúvida e/ou subjetividade. Com relação aos fatores éticos, os participantes reconhecem que a interação destas questões deve ser entre o profissional de saúde e o idoso, já que sentem-se felizes ao participar de uma pesquisa que tem por objetivo sua própria qualidade de vida.

\section{CONCLUSÃO}

Os principais resultados deste estudo inicial mostraram desafios no cenário do SAD e no formato atual do Tele-cuidado. Cita-se, por exemplo a demanda por um entendimento profundo do cenário, pois segundo um dos participantes, em um cenário, diferentes interlocutores podem ter opiniões diferentes acerca do idoso e da situação do tratamento, demandando um esforço técnico e empático do profissional de saúde. Neste sentido, tarefas repetitivas poderiam ser suportadas por tais sistemas, disponíveis todos os dias da semana e em qualquer horário [2]. À luz dos dados empíricos coletados, características sociais e econômicas no momento da elaboração dos diálogos e durante a proposta das soluções também foram identificados. Como por exemplo, o uso de mensagens que ajudem na identificação da (in)adequação do tratamento de forma que o profissional de saúde possa orientar o caminho adequado. Por fim, com relação aos próximos passos, cita-se a avaliação formativa do protótipo com outros especialistas; a definição das metas de design; o desenvolvimento da solução com base no conhecimento levantado; e a avaliação dos fenômenos de significação e comunicação no processo de melhora da alfabetização de saúde dos cuidadores através do AIC.

\section{AGRADECIMENTOS}

O presente trabalho foi realizado com apoio da Coordenação de Aperfeiçoamento de Pessoal de Nível Superior - Brasil (CAPES) - Código de Financiamento 001.

\section{REFERÊNCIAS}

[1] M. C. C. Baranauskas, M. C. Martins, and J. A. Valente. 2013. Codesign de Redes Digitais: tecnologia e educação a serviço da inclusão social. Penso Editora.

[2] K. Denecke, M. Tschanz, T. Dorner, and R. May. 2019. Intelligent Conversational Agents in Healthcare: Hype or Hope? Studies in health technology and informatics 259 (2019), 77-84.

[3] G. W. Eschweiler and L. Wanner. 2018. How Can Intelligent Conversational Agents Help? The Needs of Geriatric Patients and Their Caregivers. (2018), 1-9.

[4] L. Kebian and S. Acioli. 2014. A visita domiciliar de enfermeiros e agentes comunitários de saúde da Estratégia Saúde da Família. Revista Eletrônica de Enfermagem 16, 1 (2014), 161-9.

[5] Organização Mundial da Saúde 2011. Saúde Global e Envelhecimento. Organização Mundial da Saúde.

[6] M. Vianna. 2012. Design thinking: inovação em negócios. Design Thinking. 